\title{
Mutual Inhibition among Neural Command Systems as a Possible Mechanism for Behavioral Choice in Crayfish
}

\author{
Donald H. Edwards \\ Laboratory of Neurobiology and Behavior, Department of Biology, Georgia State University, Atlanta, Georgia 30302-4010
}

\begin{abstract}
Mutual inhibition among behavioral command systems frequently has been suggested as a possible mechanism for switching between incompatible behaviors. Several neural circuits in crayfish that mediate incompatible behaviors have been found to interact through inhibition; this accounts for increased stimulus threshold of one behavior (e.g., escape tailflip) during performance of others (eating, walking, defense). To determine whether mutual inhibition between command systems can provide a mechanism that produces adaptive behavior, I developed a model crayfish that uses this mechanism to govern its behavioral choices in a simulated world that contains a predator, a shelter, and a food source. The crayfish uses energy that must be replaced by eating while it avoids capture by the predator. The crayfish has seven command systems (FORAGE, EAT, DEFENSE, RETREAT, ESCAPE, SWIM, HIDE) that compete through mutual inhibition for control of its behavior. The model crayfish was found to respond to changing situations by making adaptive behavioral choices at appropriate times. Choice depends on internal and external stimuli, and on recent history, which determines the pattern of those stimuli. The model's responses are unpredictable: small changes in the initial conditions can produce unexpected patterns of behavior that are appropriate alternate responses to the stimulus conditions. Despite this sensitivity, the model is robust; it functions adaptively over a large range of internal and external parameter values.
\end{abstract}

Animals face a world of rapidly changing circumstances to which they must respond in a timely, adaptive manner. Many have met this challenge by drawing their behavior from sets of fixed action patterns (FAPs) released in response to specific sign stimuli (Lorenz, 1950; Tinbergen, 1951). The neural bases of FAPs have been studied in many animals, but the mechanisms used to shift behavior from one activity to another have received less attention. The observations that "an animal can scarcely do two things at a time," (111) and that strong activation of one behavior prevents activation of another, prompted the suggestion that mutual inhibition exists between centers for different behavior patterns (Tinbergen, 1951). Mutual inhibition may account for the rapid alternation between conflicting motor patterns during times of stress, such as the alternation of attack

\footnotetext{
Received Mar. 23, 1990; revised Sep. 26, 1990; accepted Dec. 7, 1990.

I would like to thank Dr. W. W. Walthall for his helpful suggestions. This work was supported by NIH Research Grant NS21136.

Correspondence should be addressed to Donald $\mathrm{H}$. Edwards at the above address.

Copyright (c) 1991 Society for Neuroscience $0270-6474 / 91 / 111210-14 \$ 03.00 / 0$
}

and flight that occurs when two conspecific fish threaten each other (Lorenz, 1982). Mutual inhibition may also produce displacement activity, when inappropriate behavior is released by disinhibition during conflict between two strongly activated motor patterns (Tinbergen, 1951; reviewed in McFarland, 1985).

Recent neurophysiological studies have begun to reveal the neural substrates of mutual inhibition. In Pleurobranchaea, a hierarchy of behavior patterns results in part from inhibition between neural command systems for different behaviors (Kovac and Davis, 1980). In crayfish, separate neuronal systems that produce different FAPs have been identified (Kennedy and Davis, 1974). These include systems that mediate the defense posture (Wiersma and Yamaguchi, 1967; Glantz, 1974), swimming (Schrameck, 1970), two forms of escape tailflip (Wine and Krasne, 1982; Krasne and Wine, 1984), walking (Bowerman and Larimer, 1973a,b; Kovac, 1974a,b; Moore and Larimer, 1987, 1988; Simon and Edwards, 1990), and swimmeret beating (Wiersma and Ikeda, 1964; Heitler and Pearson, 1980; Paul and Mulloney, 1986). Inhibition between these neuronal systems appears to account for shifts in the stimulus threshold of one activity during performance of another (Roberts, 1968; Bellman and Krasne, 1983; Krasne and Lee, 1988; Beall et al., 1990). These results support the notion of a competition among mutually exclusive behavior patterns that is mediated by inhibition between neural "command systems" for these behaviors (Krasne and Lee, 1988).

It has remained unclear, however, whether a purely competitive mechanism of decision-making can account for the adaptiveness of animal behavior (McFarland, 1974, 1985). This question is difficult to answer experimentally because the interactions of several neural systems would have to be monitored simultaneously in a behaving animal.

I have addressed this question theoretically, with a computer simulation of behavioral choice in which seven mutually inhibitory command systems compete for control of a model animal that exists in a world containing a food source, a shelter, and a predator. The simulation seeks to determine whether such a mechanism for behavioral choice can produce stable, adaptive patterns of behavior in varying contexts. The model is based on crayfish neuroethology and contains command systems for escape, retreat, defense, hiding, foraging, eating, swimming, and resting. Each system is excited by specific sensory stimuli and can initiate a unique behavioral response when in command of the model animal. Command of behavior results from a continuing competition among the command systems that is produced by mutual inhibition between them. The model crayfish must avoid the predator, find the food source, and eat it to regain the energy depleted by its activity. The model was tested to determine whether it would respond adaptively to the con- 
ditions it encounters, whether it would make smooth transitions between responses, how those responses depended on initial conditions, and on the values for the inhibitory coefficients that govern command system interactions.

\section{Materials and Methods}

The simulation of crayfish behavior is expressed by a QUICKBASIC computer program called CRAYFISH, which is run in compilcd form on personal computers that support MS DOS. Both compiled code and source code are freely available from the author when a disk formatted for MS DOS is supplied with the request. Arbitrary units of distance $(d)$, time $(t)$, food $(f)$, energy $(e)$, excitation, and inhibition are used in the simulation.

\section{The simulated world external to the CRAYFISH}

The locations of the food and shelter, the initial location of the model crayfish (hereafter called the CRAYFISH) and the initial location and time of appearance of the predator in the simulation are specified before each run. The predator appears with an initial direction and cruising speed of movement. If while cruising it comes within a fixed distance of the CRAYFISH, it will give chase and double its speed. If the $C R A Y$ FISH escapes to outside that distance or into its shelter, the predator will give up the chase and resume cruising speed and direction. The $C R A Y F I S H$ is considered to have been caught and eaten if the predator comes into contact with it.

\section{Organization of the CRAYFISH: Competition among command systems}

The CRAYFISH's behavior is governed by one of seven "command systems": ESCAPE, RETREAT, DEFENSE, HIDE, EAT, FORAGE, and SWIM. Each command system is excited by a limited set of external or internal stimuli and inhibited by other command systems, so that its response, or "command value," is equal to its excitation minus the summed inhibition. When the command value exceeds a constant threshold of 1 , the system can inhibit other systems, and when its command value exceeds 4 it can gain control of the model's behavior. When two or more systems are simultaneously above this behavioral threshold, control will remain with the system that has been above threshold longest. If none of the command systems are above threshold, the behavior is in a default state, REST. The behavior produced by the controlling command system changes the relationship of the $C R A Y$ FISH to both external stimuli (predator, food source, shelter) and internal stimuli (energy), and so aiters the pattern of sensory stimuli that the CRAYFISH receives. The altered pattern of stimuli will change the competition among command systems and may enable another command system to gain control of behavior.

\section{Excitation of command systems}

ESCAPE, RETREAT, DEFENSE, and SWIM. ESCAPE, RETREAT, and DEFENSE are each excited by the approach of a predator, but to different degrees and at different distances. As a predator approaches at either cruising $(2 d / t)$ or chase $(4 d / t)$ speeds, DEFENSE initially will be excited most strongly, succeeded by RETREAT, and then ESCAPE as the predator draws near. DEFENSE keeps the CRAYFISH in place (and has no effect on the predator), while RETREAT moves the $C R A Y$. $F I S H$ away from the predator and towards the shelter at a slow rate (2 $d / t)$. ESCAPE is a rapid ballistic movement directly away from the predator $(50 \mathrm{~d} / \mathrm{t})$, whereas SWIM moves the CRAYFISH away from the predator and towards the shelter at a slower rate $(25 d / t)$. SWIM is excited reflexively during the ESCAPE. Finally, RETREAT is also modestly excited in the absence of a predator by the nearness of the shelter; this excitation is greatest at the shelter and decreases with increasing distance from it. This excitation causes CRAYFISH to move into the shelter when it is nearby and other stimuli (e.g., hunger or a predator) are absent.

$H I D E, F O R A G E, E A T$, and REST. HIDE receives constant excitation when the CRAYFISH enters the shelter, which is a circle of 20 $d$ radius. Outside the shelter, HIDE is not excited. HIDE is a stationary behavior, and acts to inhibit other behaviors that would move $C R A Y$ FISH out of the shelter. FORAGE is excited both by the local food odor and by hunger. Food odor at the CRAYFISH is proportional to the size of the food source and inversely proportional to the distance between the source and the CRAYFISH. Hunger depends on the energy available to the $C R A Y F I S H$, and it increases as the energy level falls during activity and decreases during EAT as the CRAYFISH gains energy. FORAGE moves the CRAYFISH up the odor gradient towards the food source as $3 d / t$. EAT is excited identically to FORAGE, but only when the CRAYFISH contacts the food source (i.e., less than 10 $d$ away). EAT is a stationary behavior that rapidly increases the energy level of the CRAYFISH, and also decreases the food source by an equal amount. The default behavior, REST, keeps the animal stationary and has no inhibitory effect on other systems.

The excitation of each system is limited to a maximum of 20 . The equations that describe this excitation are given in the Appendix.

\section{Mutual inhibition among command systems}

When a system's command value is greater than or equal to 1 , it inhibits other systems according to the product of its command value and an inhibitory coefficient. Otherwise, the inhibition is 0 . The inhibitory effect is a simple subtraction of the inhibitory amplitude from the inhibited system's command value. The coefficients for different pairs of inhibiting and inhibited systems are different, and these differences help express the relative priorities of the systems. (For the set of inhibitory coefficients, see Table 1.)

\section{Energy expenditure and gain}

The initial energy store changes during a simulation as the CRAYFISH moves about the screen and eats. Each behavior except eating has a metabolic cost that varies with the animal's rate of movement. These costs are given in the Appendix.

\section{Results}

Adaptiveness of behavior: avoidance of a predator and satiation of hunger

$C R A Y F I S H$ responds adaptively to rapidly changing circumstances when it is hungry in the presence of a food source and when it is attacked by a predator. These responses are demonstrated in three simulations (see Figs. 1-3) in which CRAYFISH encountered a predator at different times during its cycle of hiding, foraging, and eating. Except for the times of appearance of the predator (at $100 t, 200 t$, and $235 t$ ), all the parameter values and initial conditions of the three simulations were identical. In each, $C R A Y F I S H$ was initially positioned in the upper center, away from both the food source and shelter. The food source contained $5 f$ and the $C R A Y F I S H$ was moderately hungry (initial energy content was $1 e$ ). The predator was set to appear on the upper left side of the computer screen and to cruise at a speed of $2 d / t$ towards the lower right corner. When the predator came within $100 d$ of the CRAYFISH, it gave chase at $4 d / t$ until it either caught the CRAYFISH or the CRAYFISH moved beyond $100 d$ away.

First simulation: predator appears at $50 \mathrm{t}$. At the beginning of the first simulation, CRAYFISH was outside the shelter (S, Fig. $1 A$ ), but near enough so that RETREAT was excited above the behavioral threshold of 4 (Fig. $1 B, C$ ). Governed by RETREAT, CRAYFISH moved towards the shelter, where it arrived at $49 t$ (Fig. 1 $A$ ). HIDE was strongly excited as $C R A Y F I S H$ entered the shelter, and its command value crossed both the inhibitory and behavioral thresholds (Fig. 1C). This inhibition pushed RETREAT below its behavioral threshold and allowed HIDE to take control at $52 t$ (Fig. $1 B$ ).

As HIDE kept CRAYFISH in the shelter, FORAGE became increasingly excited as energy gradually fell (Fig. $1 C$ ). Inhibition from HIDE prevented the command value of FORAGE from crossing behavioral threshold, but that inhibition was itself reduced by reciprocal inhibition from FORAGE. The predator appeared at $50 t$, but only began to excite DEFENSE and RETREAT much later (at $190 t$ ) as it approached the shelter. DE- 

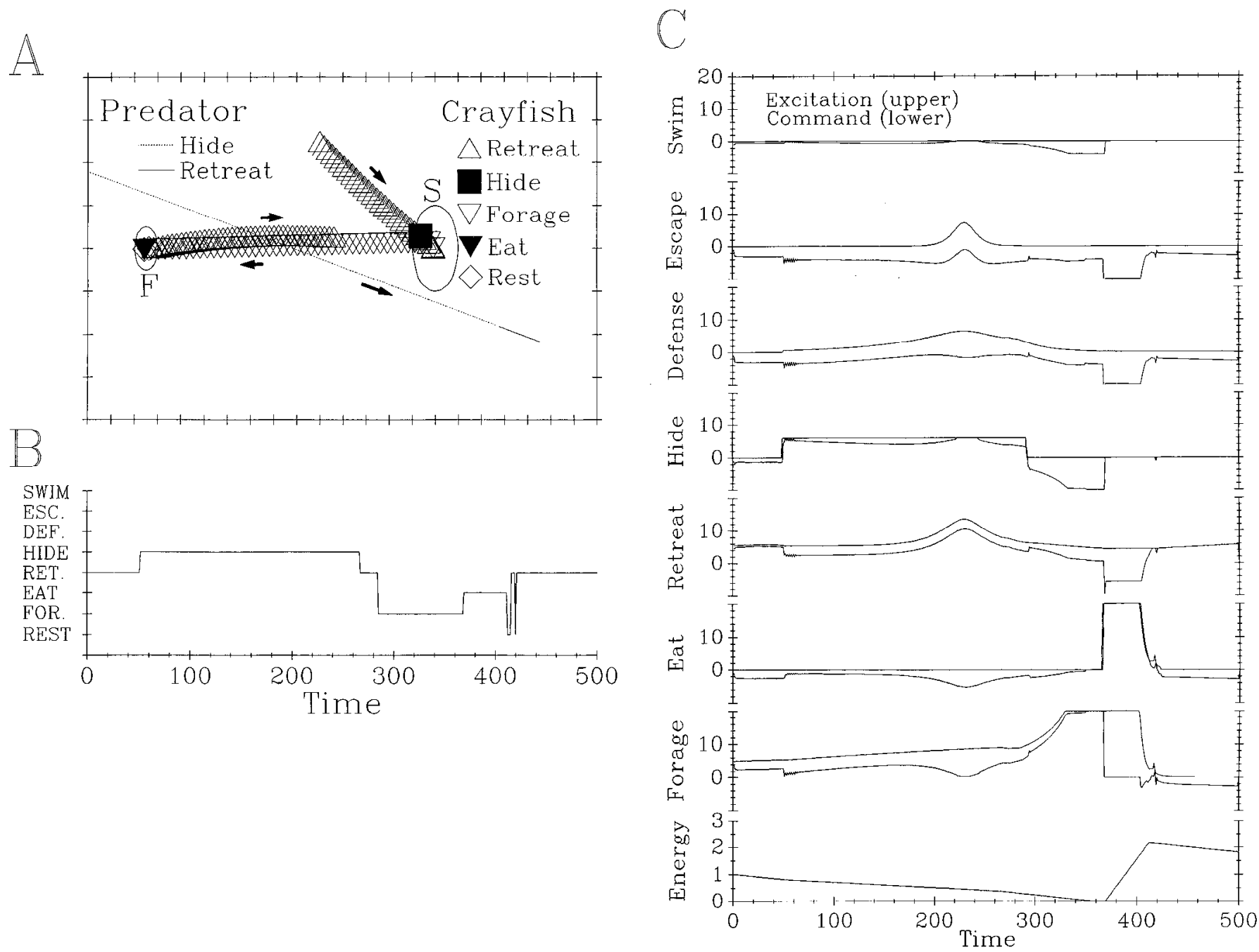

Figure 1. CRAYFISH movements, sequences of behavior, and command system excitation and responses during the first simulation, in which the predator entered at $50 \mathrm{t} . A, C R A Y F I S H$ and predator movements as different systems take control. The tick marks on the horizontal and vertical axes denote equal distances. The position of the shelter $(S)$ and food $(F)$ are indicated by the large open ovals. The large symbols represent both the position of the predator every $2 t$ and the command system in control of CRAYFISH, according to the key at right. The arrows indicate the direction of movement; the simulation begins with CRAYFISH in the upper middle of the field. The path of the predator during different command states of CRAYFISH is indicated by the different line segment symbols identified in the key at left. $B$, Sequence of command systems controlling CRAYFISH behavior. C, Plots of the excitation each command system receives (always the upper line in each panel) and the command valucs (the lower lines) during the simulation. Inhibitory threshold for each system is 1 ; behavioral threshold is 4 . A plot of energy is given in the bottom panel.

FENSE and RETREAT were strongly inhibited by HIDE, FORAGE, and RETREAT, but excitation of RETREAT caused its command value to increase and inhibit FORAGE. This inhibition effectively disinhibited HIDE, which retained control of behavior. As energy continued to decline, however, the excitation of FORAGE increased as did its inhibition of HIDE, which fell below behavioral threshold. RETREAT remained above threshold and took over control of behavior at $267 \mathrm{t}$.

RETREAT moved CRAYFISH to the center of the shelter, where it remained. As the predator moved beyond the shelter (Fig. $1 A$ ), the command value of RETREAT declined while FORAGE continued to increase. RETREAT fell below behaviural threshold shortly after FORAGE exceeded it, and so behavioral control passed to FORAGE at $285 t$.

FORAGE moved CRAYFISH away from the shelter and up the food odor gradient towards the food source (F, Fig. 1A). The excitation of FORAGE increased quickly as the movement caused the food odor to increase and energy to decrease. The strong response of FORAGE enabled it to inhibit all other systems except EAT. Once CRAYFISH reached the food source, EAT became excited and inhibited FORAGE and all other systems except HIDE and SWIM.

EAT gained control of behavior at $369 t$, and energy quickly increased. This reduced the excitation of both EAT and FORAGE and so reduced their inhibition of ESCAPE, DEFENSE, and RETREAT. EAT fell below behavioral threshold (at $411 t$ ) before RETREAT could exceed its own threshold and so $C R A Y$ FISH RESTed for a brief period before RETREAT gained control at $416 t$.

As CRAYFISH moved towards the shelter, it passed by the food source. FORAGE was briefly excited and exceeded inhibitory threshold which caused RETREAT to fall briefly below 

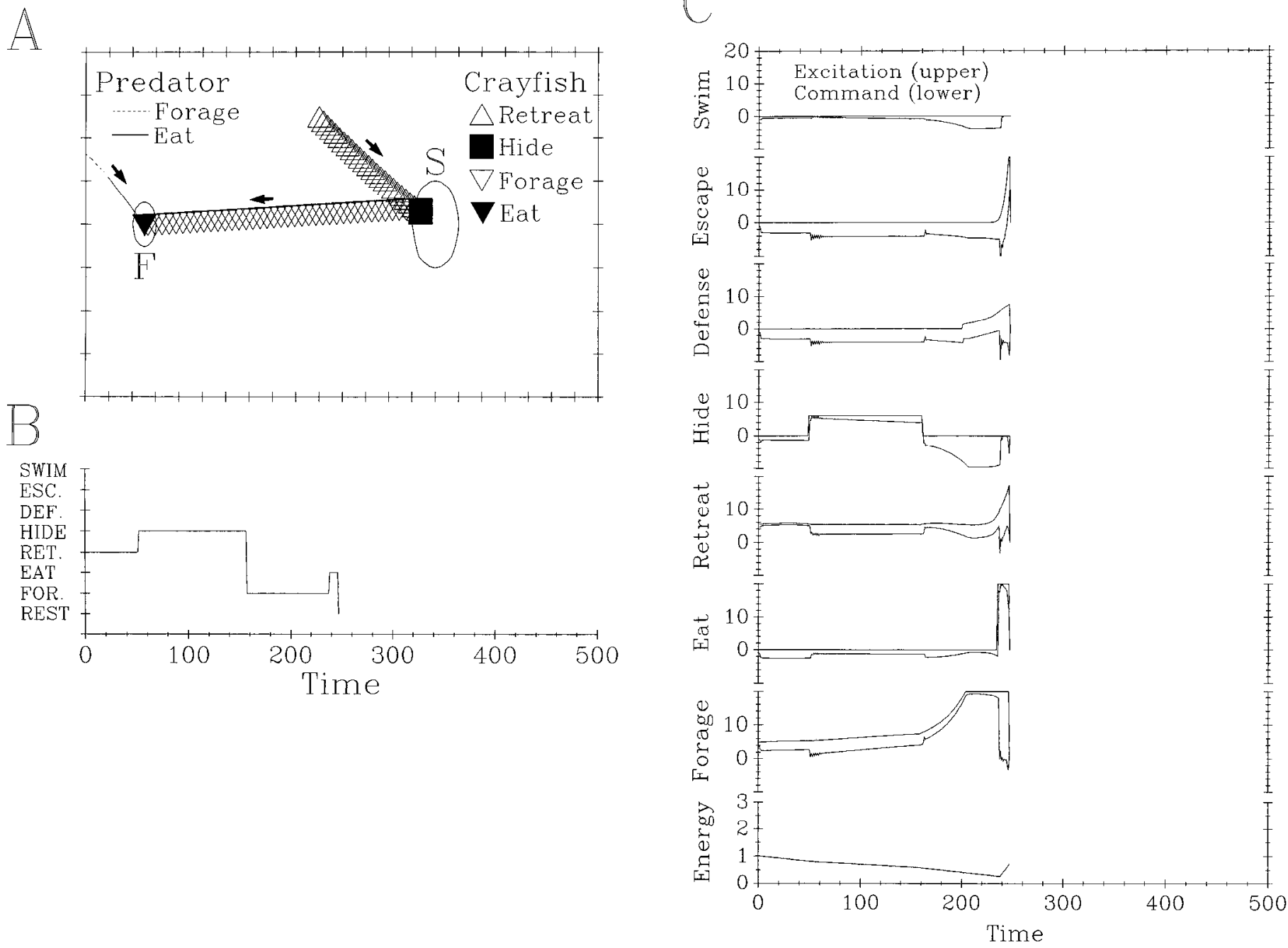

Figure 2. Second simulation, in which the predator enters at $50 t$ and catches $C R A Y F I S H$ EATing. $A, B$, and $C$ as in Figure 1 .

behavioral threshold at $420 t$. CRAYFISH then RESTed for 1 $t$ before RETREAT regained control and movement towards the shelter resumed.

Second simulation: predator appears at $200 t$. CRAYFISH avoided the predator in the last simulation by remaining in the shelter until it had passed by. In this simulation, the predator appeared later and caught CRAYFISH just as it had begun to EAT.

The initial events in the second simulation were identical to those of the first: RETREAT moved CRAYFISH to the shelter where HIDE gained control (Fig. $2 A, B$ ). In the absence of the predator, however, RETREAT failed to inhibit FORAGE which increased as energy fell (Fig. 2C). FORAGE crossed behavioral threshold at $155 t$, and its inhibition of HIDE caused that system to fall below threshold at $156 t$. This permitted FORAGE to take control, and so CRAYFISH began to move towards the food source at $157 \mathrm{t}$, much earlier than in the first simulation (Fig. 2A,B).

As before, FORAGE increased rapidly as CRAYFISH approached the food source and this allowed FORAGE to inhibit RETREAT, DEFENSE, and ESCAPE. The inhibition suppressed their responses to the predator, which appeared just before CRAYFISH arrived at the food source at $235 t$.
EAT was strongly excited and replaced the inhibition of ESCAPE, RETREAT, and DEFENSE produced by FORAGE with its own inhibition. Energy began to increase and the excitation of EAT fell, but at the time of the predator's allack (at $240 l$ ) EAT strongly inhibited the three predator avoidance systems. The attack of the predator strongly excited ESCAPE, RETREAT, and DEFENSE, but they failed to inhibit EAT suffciently to drive it below behavioral threshold and allow one of them to take over. CRAYFISH was caught by the predator at $246 t$.

Third simulation: predator appears at $235 t$. CRAYFISH was also caught when the predator appeared earlier (at $100 t$ ), as CRAYFISH approached the food source, and when the predator appeared slightly later (at $225 t$ ), while CRAYFISH was still EATing. When the predator did not appear until $235 t$ (Fig. $3 A$ ), EATing increased energy so that EAT no longer inhibited ESCAPE (Fig. 3B,C). The strong excitation of ESCAPE enabled its inhibition to drive EAT below behavioral threshold and to take control at $274 t$. ESCAPE moved CRAYFISH $150 d$ directly away from the predator in $3 t$, when SWIM took control and moved CRAYFISH back to the shelter in the next $6 t$ (Fig. $3 A$ ). The reflex excitation of SWIM by ESCAPE fell below behavioral threshold 1 time unit before HIDE was excited by entering the 

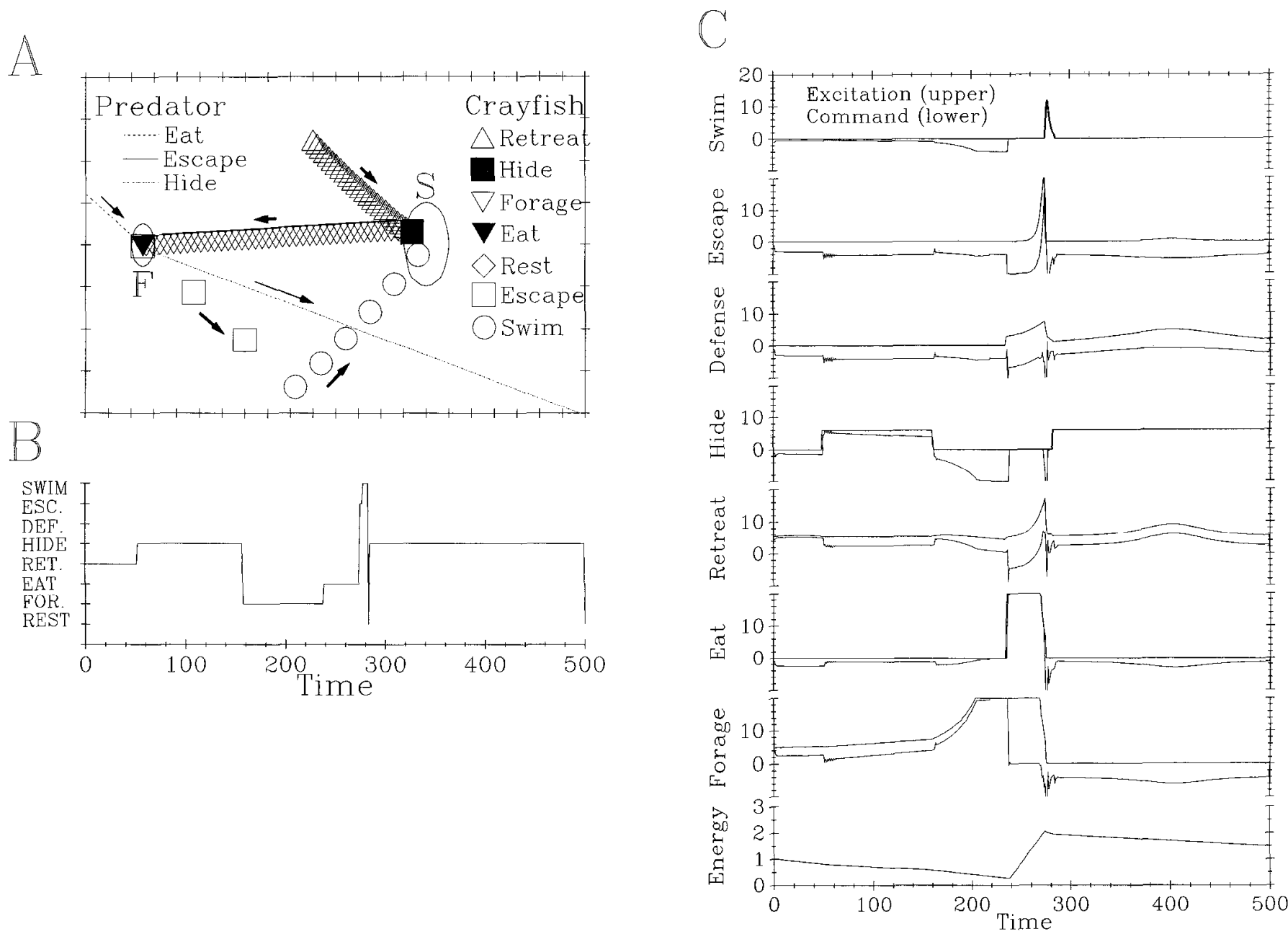

Figure 3. Third simulation, in which the predator enters at $235 t$ and the CRAYFISH escapes back to the shelter. $A$, Movement of CRAYFISH every $1 t$ is shown during ESCAPE and SWIM. $B$ and $C$ as in Figure 1 .

shelter, and so CRAYFISH RESTed briefly before HIDE took control at $284 t$ (Fig. 3B,C).

Following the escape of $C R A Y F I S H$, the predator resumed cruising in its original direction. CRAYFISH remained in the shelter controlled by HIDE, but as the predator passed, RETREAT and DEFENSE were weakly excited.

These simulations demonstrate that $C R A Y F I S H$ can respond to changing situations by making adaptive behavioral choices at appropriate times. Choice depends on both internal (energy) and external stimuli (relative positions of crayfish, predator, food source, and shelter), and on recent history, which determines the strength and spatial pattern of those stimuli.

\section{Unexpected appearance of alternate behavior patterns as the} initial value of one parameter is gradually changed

The three simulations demonstrated that changes in one parameter, the predator's time of appearance, can lead to large changes in the sequence of behaviors displayed by $C R A Y F I S H$. While this is not surprising, it prompts the question of whether continuous change in the initial values of other parameters, such as the size of the food source or the amount of energy available, leads to gradual or abrupt changes in the temporal pattern of behavior displayed by $C R A Y F I S H$.
To address this question, a series of simulations were run in which no predator appeared, the initial positions of $C R A Y$ $F I S H$, the food source, and the shelter were kept as before, the amount of energy initially available remained $1 e$, and the initial amount of food in the food source was varied $0-10 f$ in $0.1 f$ increments in succeeding simulations. Each simulation was run for at least $500 t$. The sequence of behaviors produced by several of these simulations are shown in Figure 4.

When the initial amount of food was 3.6 or less, CRAYFISH RETREATed from its starting position to the shelter, where HIDE took over and kept it there for the duration (Fig. $4 A$, top panel). With food set initially to $3.7 f, C R A Y F I S H$ switched to FORAGE at $398 t$, emerged from the shelter, and arrived at the food at $480 t$, when it began to EAT. A similar sequence occurred when food was set initially to $3.8 \mathrm{f}$, except that FORAGE began earlier, at $351 t$ (Fig. $4 A$, panel 2). This was followed by $1 t$ of REST, after which FORAGE resumed and CRAYFISH arrived at the food at $433 t$ and triggered EAT. EATing was followed by REST for $4 t$, when RETREAT gained control and $C R A Y$ $F I S H$ returned to the shelter.

The same pattern of behavior occurred in each simulation as the initial food amount was increased from $3.8 f$ to $4.9 f$, except that the duration of HIDE dropped continuously while the du- 

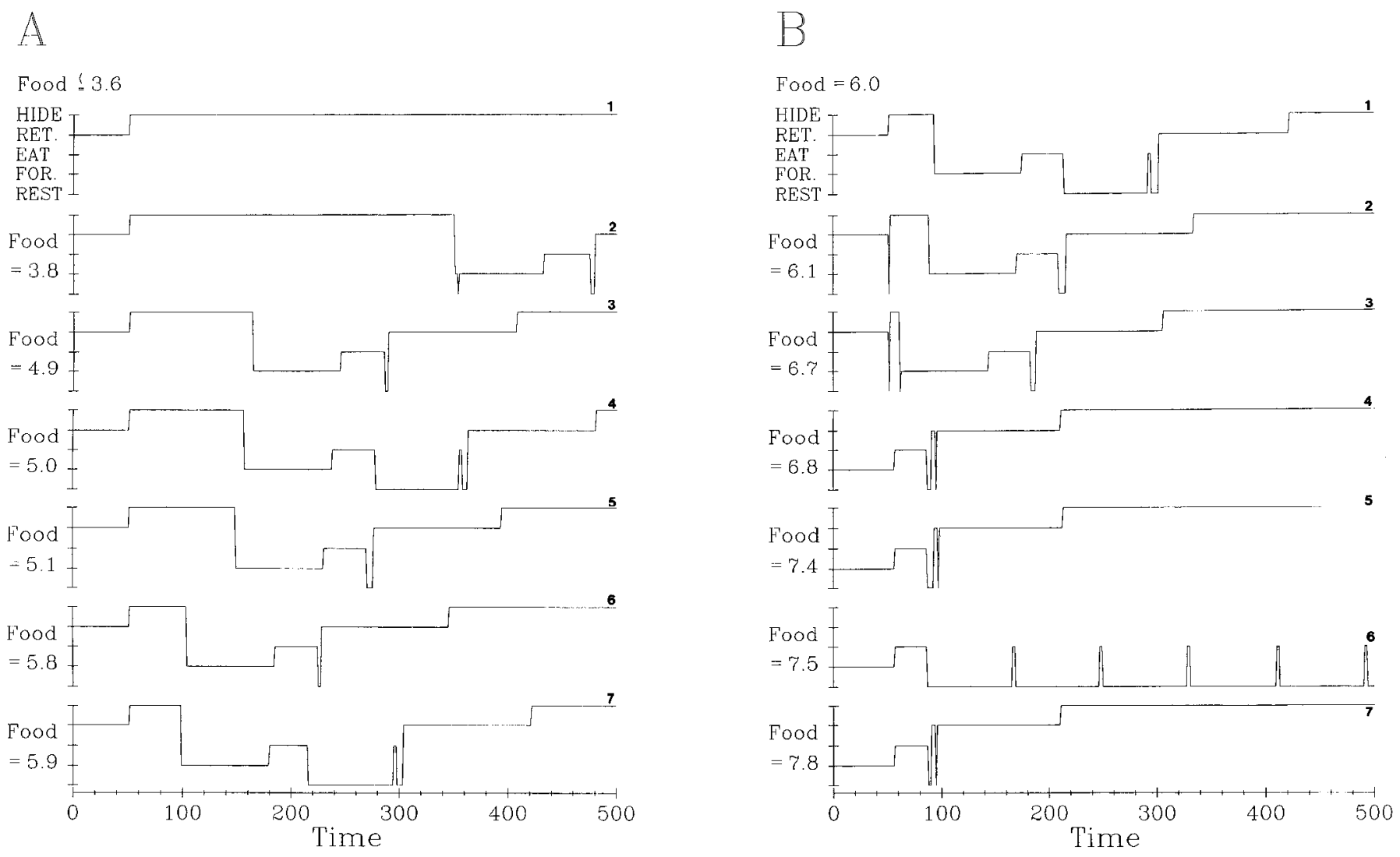

Figure 4. Changes in behavior pattern in response to small changes in the initial amount of food, which was varied from 0 to $10 f$ in $0.1 f$ steps. Each panel shows the sequence of behaviors in response to one initial amount of food. Panels were chosen to illustrate gradual and sudden transitions in behavior pattern as the food amount changes. $A$, Food varied from $3.6 f($ top panel) to $5.9 f($ bottom). $B$, Food varied from $6.0 f($ top panel $)$ to $7.8 f($ bottom $)$.

ration of other behaviors fell only slightly (Fig. $4 A$, panel 3 ). When food was set initially to $5.0 f$, however, a new pattern of behavior occurred after EATing (Fig. 4A, panel 4). Instead of the short period ( $3 t$ ) of REST that followed EAT in the $4.9 f$ simulation, REST lasted $77 t$ in the $5.0 f$ simulation, and was followed by another brief bout of EAT before RETREAT took control.

When the initial food amount was increased to $5.1 \mathrm{f}$, the first pattern of behavior reappeared with only slight differences from that seen at $4.9 f$ (Fig. $4 A$, panel 5). This pattern persisted in each simulation as the initial food amount increased to $5.8 \mathrm{f}$ (Fig. $4 A$, panel 6): the duration of the initial HIDE response decreased with each increase in food and each of the subsequent behaviors occurred that much earlier.

When the initial food amount was increased to $5.9 \mathrm{f}$, the second pattern reappeared (Fig. $4 A$, panel 7) and was maintained at $6.0 f$ (Fig. $4 B$, panel 1). At $6.1 f$, however, the first pattern reappeared and governed behavior in subsequent simulations as the food amount was increased to $6.7 f$ (Fig. $4 B$, panels 2 and 3).

At $6.8 f$, a new pattern appeared as CR.4YFISH began the simulation by FORAGEing rather than RETREATing to the shelter (Fig. 4B, panel 4). EATing began when CRAYFISH arrived at the food, but lasted for a shorter period because more of the initial amount of energy still remained. EAT was followed by two cycles of a rapid alteration between REST and RETREAT, a pattern seen previously in Figure $1 B$. RETREAT moved CRAYFISH back to the shelter where HIDE took control at $211 t$.

This same pattern occurred nearly without change as the initial food amount was increased from $6.8 f$ to $7.4 f$ (Fig. $4 B$, panel 5). At $7.5 f$, however, a completely new pattern appcarcd in which repeated cycles of short bouts of EATing and long periods of REST followed the initial period of EATing (Fig. $4 B$, panel 6). This intermittent "snacking" lasted until $665 t$, when RETREAT took control and moved CRAYFISH to the shelter. The previous pattern then reappeared when the food amount was raised to $7.8 f$, but bouts of "snacking" also occurred for initial food amounts between $8.9 f$ and $9.2 f$.

Sudden changes in the behavior pattern were also seen when other single parameters, including the initial amount of energy and the distance between the food source and the shelter, were each varied incrementally over a range of values.

\section{System thresholds and abrupt changes in behavior}

The unexpected, abrupt changes in the pattern of $C R A Y F I S H$ behavior prompted the question of how the interactions of command systems produce this behavior. Analysis of one transition demonstrated that small differences in the command value of a system that is near the inhibitory or behavioral threshold can strongly affect the subsequent behavior pattern.

Figure 5 presents the excitation and command functions for RETREAT, EAT, and FORAGE during two of the simulations shown in Figure $4 A$, when food was initialy set to $4.9 f$ and 5.0 
Figure 5. Change in energy (top), excitation of RETREAT, EAT, and FORAGE (panels 2-4), their command values (panels 5-7), and the behavior sequence (bottom) in response to a 0.1 $f$ difference in initial food amount. Excitation and command values $>10$ and $<0$ are not shown. From simulations with food equal to $4.9 f$ and $5.0 f$ in Figure 4.

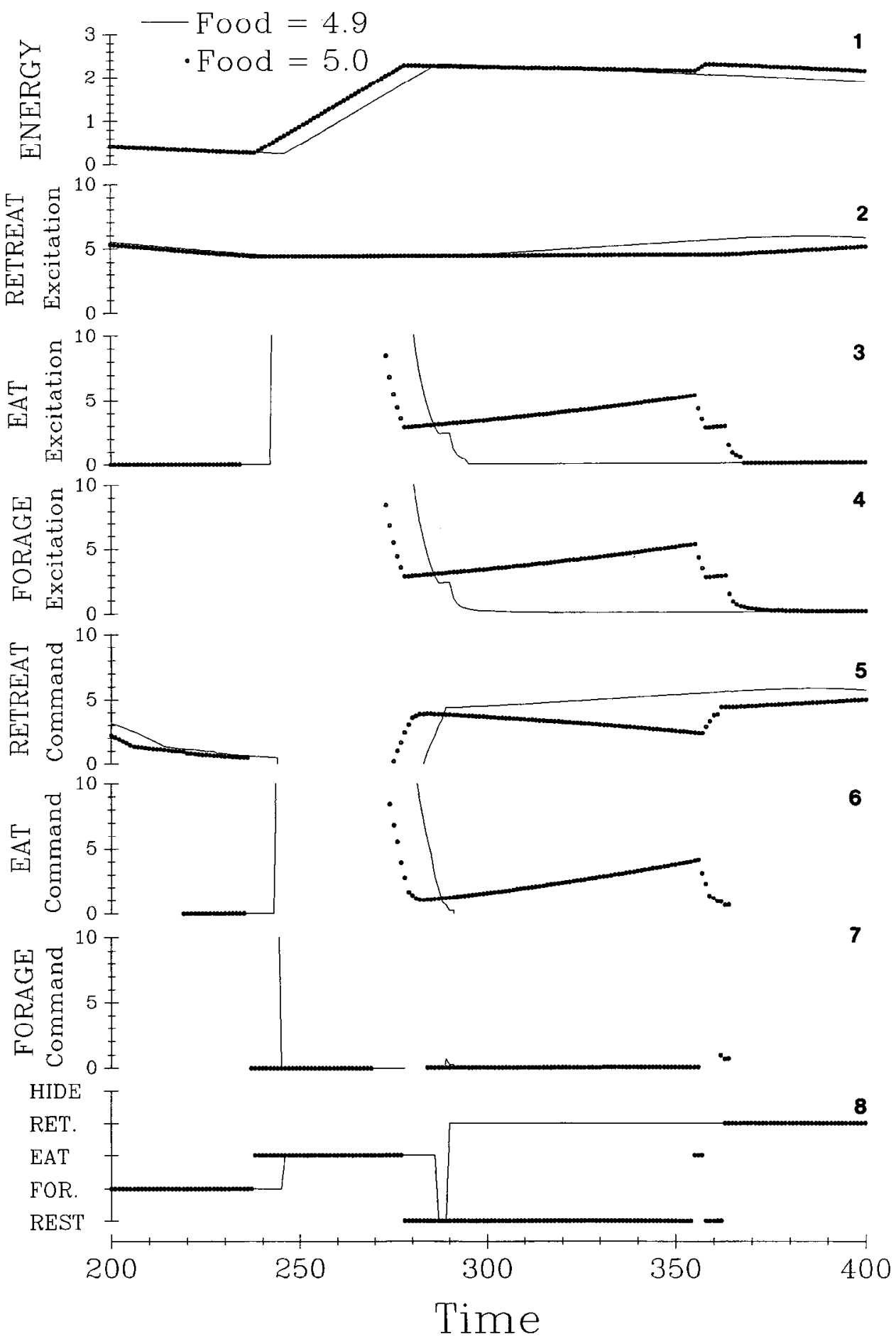

$f$. The bottom panel of Figure 5 displays the behavior sequences seen earlier: In the 4.9- $f$ simulation, $C R A Y F I S H$ RESTed only briefly following EATing and before RETREATing, whereas at $5.0 \mathrm{f}, \mathrm{CRAYFISH}$ had a much longer REST before a final brief bout of EATing and the beginning of RETREAT. This difference occurred because the additional food available in the 5.0- $f$ simulation caused CRAYFISH to spend $12 t$ less time in the shelter and thereby to have more energy $(0.266 e$ vs. $0.250 e)$ when it arrived at the food source and began to EAT. This larger energy level allowed CRAYFISH in the 5.0-f simulation to spend $1 t$ less time EATing, which caused it to have less energy and con- sequently a higher command value of EAT when it stopped EATing than did CRAYFISH in the 4.9-f simulation (Fig. 5, panels 3 and $6 ; 260 t-290 t$ ). The command value of EAT was then below behavioral threshold in both simulations, so that $C R A Y F I S H$ began to REST. In the 4.9-f simulation, but not in the 5.0- $f$ simulation, EAT was also below the threshold for inhibition, so that RETREAT was disinhibited (Fig. 5, panel 5). Disinhibition allowed RETREAT to cross behavioral threshold and gain control of behavior; in the 5.0- $f$ simulation, inhibition of RETREAT kept it below behavioral threshold and $C R A Y F I S H$ continued to REST. 

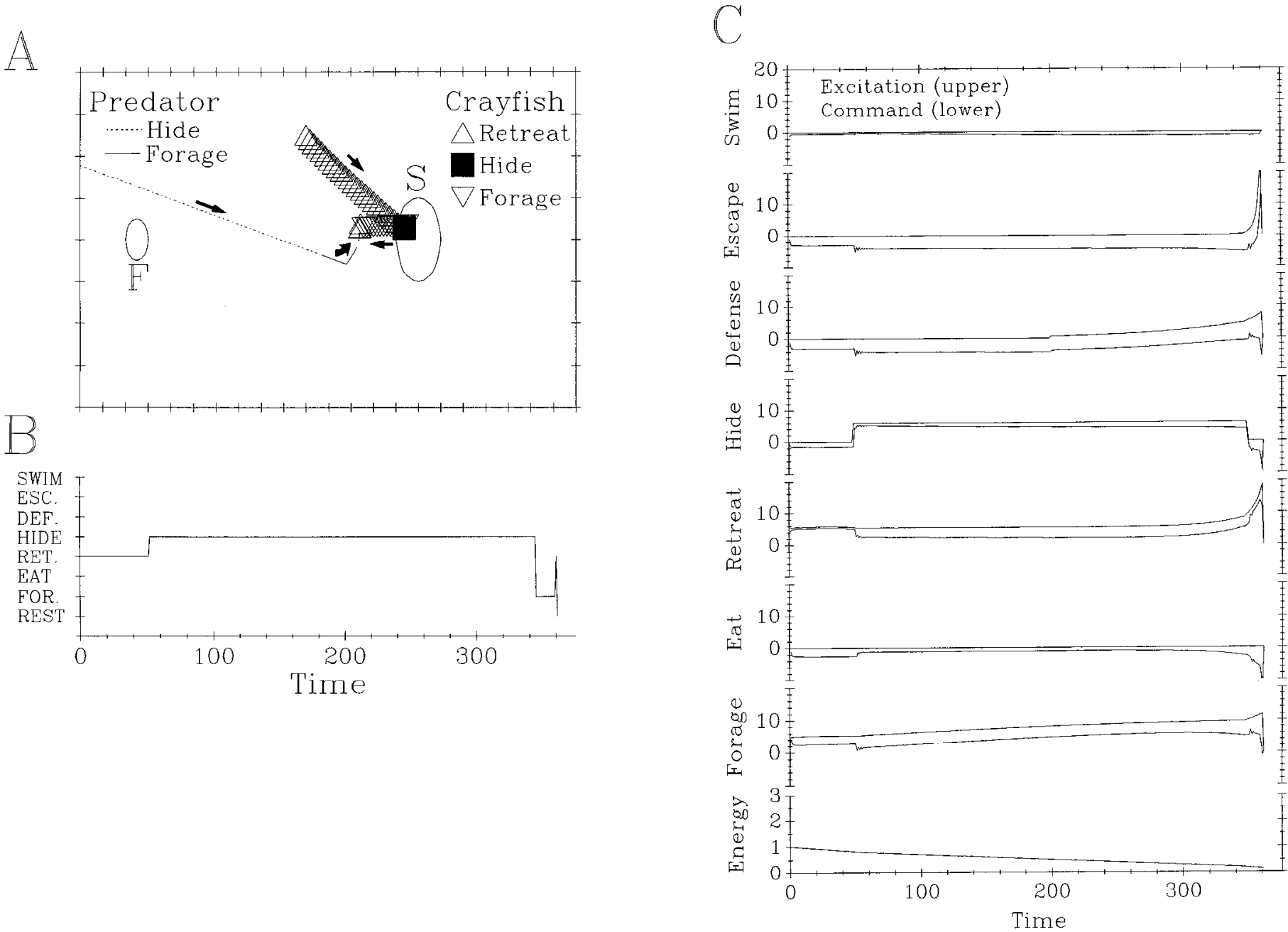

Figure 6. Displacement behavior evoked by approach of the predator, after the coefficient of inhibition of HIDE by RETREAT was changed from 0 to 0.2. Other conditions werc as in Figure 1. A, CRAYFISH and predator movements. $B$, Sequences of $C R A Y F I S H$ behavior. $C$, Command system excitation and responses.

\section{Changes in the model parameters and displacement behavior}

The observation that small changes in external parameters can have significant effects on CRAYFISH behavior prompted the question of whether small changes in the internal parameters, such as the inhibitory cocfficients (sce Table 1), would have similar effects on behavior. In some cases they do: when the coefficient for inhibition of EAT by ESCAPE was decreased from 1.0 to $0.8, C R A Y F I S H$ failed to escape from the predator in a replay of the simulation described in Figure 3. The same thing happened when the coefficient for inhibition of ESCAPE by EAT was increased from 0.5 to 0.6 .

Other small changes in inhibitory coefficients can produce qualitative changes in the kind of behavior produced by $C R A Y$ $F I S H$. In the present model, the coefficient for inhibition of HIDE by RETREAT is 0 . When that coefficient was changed to 0.2 and the initial conditions were set to those of the simulation in Figure 1, displacement behavior occurred during CRAYFISH's encounter with the predator (Fig. 6). Displacement behavior occurs when an animal performs an inappropriate behavior, such as grooming, when it is in a stressful situation that might otherwise evoke conflicting responses such as fight or flight (Tinbergen, 1951; Lorenz, 1982). In this instance
(Fig. 6), CRAYFISH was HIDEing in the shelter when the approach of the predator excited RETREAT, which then inhibited HIDE and allowed FORAGE to take over inappropriately. CRAYFISH then emerged from the shelter and was immediately captured by the nearby predator.

\section{Robustness of CRAYFISH}

The previous results demonstrate the sensitivity of CRAYFISH behavior to the specific values of external and internal parameters. It is still unclear whether the range of internal parameter values that allows $C R A Y F I S H$ to produce adaptive behavior is large or small. This question was addressed by testing $C R A Y$ FISH in the same stimulus situations as before, but after the inhibitory coefficients had been changed by a constant factor. Very little change occurred in CRAYFISH behavior when the coefficients were increased by $20 \%$ and when they were decreased by half. When they were increased by $50 \%$, the command values of HIDE, FORAGE, and RETREAT experienced brief periods of oscillation as $C R A Y F I S H$ became hungry while HIDEing in the shelter (Fig. 7). CRAYFISH was still able to avoid a predator that entered late, as CRAYFISH was about to finish EATing.

Other combinations of values exist for the excitatory and 

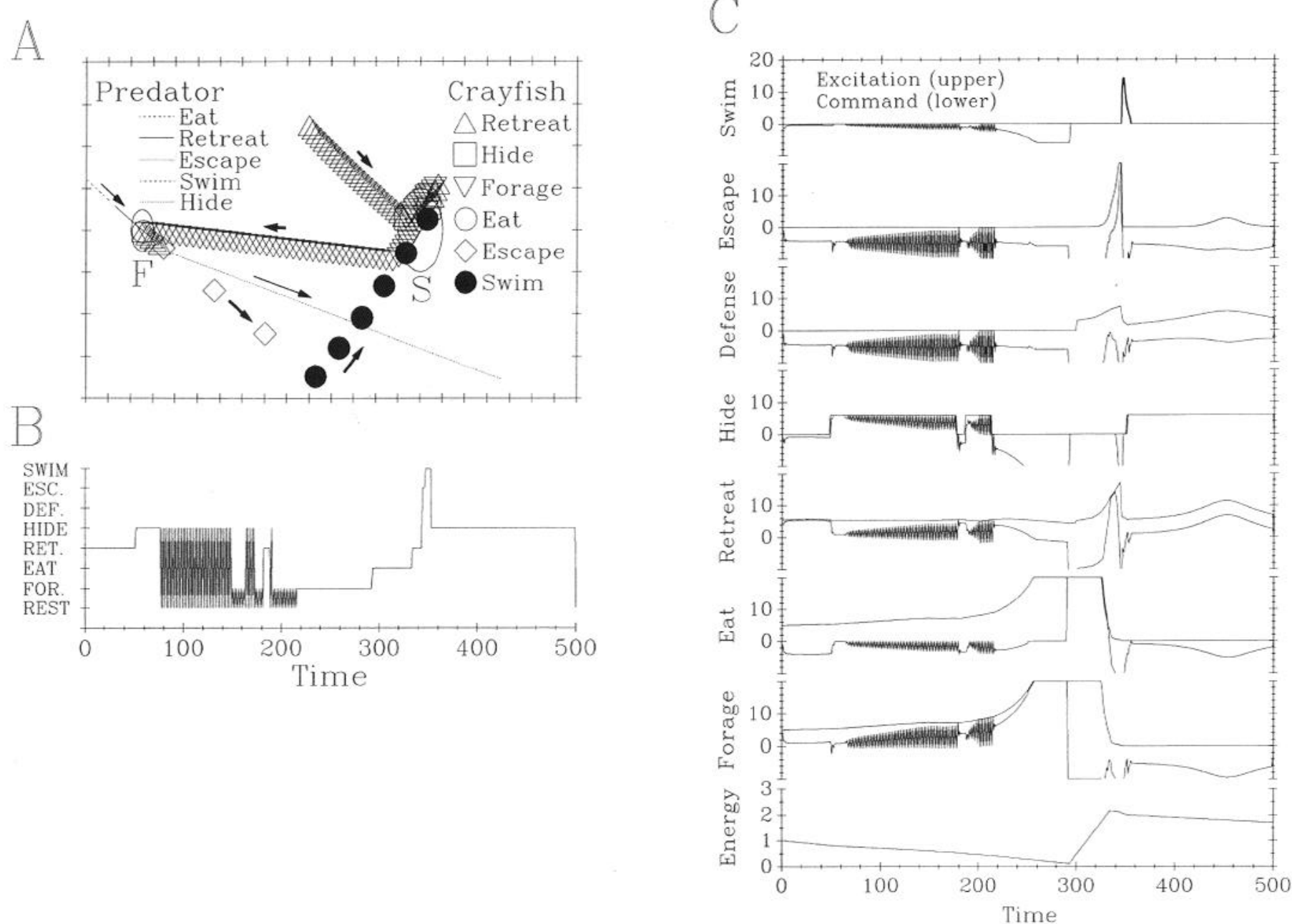

Figure 7. Periods of oscillation in CRAYFISH responses after inhibitory coefficients were increased by $50 \%$. Initial conditions same as in Figure 2, except predator entered at $300 t$. A, CRAYFISH and predator movements. B, Sequences of CRAYFISH behavior. C, Command system excitation and responses.

inhibitory coefficients and the inhibitory and behavioral thresholds that allow adaptive choices by CRAYFISH. When (1) the excitatory coefficient for escape ( $A_{\text {esc }}$ in Equation 5) was increased to $100,(2)$ all the nonzero inhibitory coefficients (see Table 1) were set equal to 1 , (3) the thresholds for producing inhibition and controlling behavior were also set equal to 1, and (4) the initial conditions were identical to those of the simulation of Figure 3, then the sequence of CRAYFISH's behavior was like that shown in Figure 3. CRAYFISH's behavior was little changed when the inhibitory coefficients were increased to 1.2 , but periods of oscillation occurred in the behavior and command system responses when the coefficients were increased to 1.5. When the inhibitory coefficients were set equal to 2 , the oscillations became uncontrolled and persisted indefinitely.

While all combinations of coefficient and threshold values for CRAYFISH have not been tested, these results show that more than 1 combination can produce smooth, adaptive transitions between behaviors. Moreover, CRAYFISH remains well behaved even when coefficient values of a combination are changed by $20 \%$ or more.

\section{Crayfish escape and speed of the predator}

CRAYFISH managed to avoid being caught by the predator when it attacked at $4 d / t$, except when FORAGE and EAT were being strongly excited. The CRAYFISH can also avoid being caught by predators with attack speeds below $10 \mathrm{~d} / \mathrm{t}$ under all but these same circumstances. When FORAGE or EAT are excited, higher attack speeds enable the predator to catch $C R A Y$ $\mathrm{FISH}$ at distances farther from the food source. This situation can be reversed by increasing the distances at which the predator excites DEFENSE, RETREAT, and ESCAPE (i.e., increase $L_{\text {def }}$, $L_{\text {ret }}$, and $L_{\text {esc }}$ in Equations 3, 4, and 5, respectively).

\section{Discussion}

\section{Adaptive and unpredictable behavior of CRAYFISH}

At the outset of this study it seemed possible that no combination of excitatory and inhibitory coefficients would allow $C R A Y F I S H$ to make adaptive and smooth transitions between behaviors under all the different stimulus situations it would encounter. CRAYFISH could conceivably be subject to oscillations in response to some combination of stimuli or to becoming hung up in one behavioral state, unable to extricate itself. These fears proved groundless. The simulations show that $C R A Y F I S H$ can respond adaptively to complex and rapidly changing stimulus situations. This success supports the suggestion that mutual inhibition between neural circuits for competing behaviors should be considered seriously as a possible mechanism of behavioral choice. 
One of the unexpected findings of the study is that like much of animal behavior, the response sequences of CRAYFISH are frequently unpredictable. Part of this unpredictability results from CRAYFISH's sensitivity to the initial conditions of the simulation, in particular to small differences in the pattern of sensory stimuli. As was shown, the earlier or later appearance of the predator, or the provision of more or less food can change the timing or choice of a behavioral transition. This change in response produces a corresponding change in the subsequent stimulus configuration, and so begins an increasing separation in the response histories of two initially similar situations.

\section{Mechanisms for adaptive decisions in CRAYFISH}

The adaptiveness of CRAYFISH's responses results from its ability to detect the relevant stimuli, judge their relative urgency, and produce an appropriate response based on that judgment. These different functions are carried out by different parts of the decision-making mechanism. First, each system is excited by a unique stimulus configuration and produces a behavioral command that is an appropriate response to the stimulus. For instance, approach of the predator produces the greatest excitation first in DEFENSE, then in RETREAT, and finally in ESCAPE as the predator draws close to the CRAYFISH. Second, mutual inhibition enhances differences between the responses of competing command systems to reduce the number of systems currently above behavioral threshold. This process is weighted by the relative sizes of the excitatory and inhibitory coefficients, which help determine behavioral priorities. It is followed by selection of the system that has been above behavioral threshold longest. Finally, the behavioral responses serve to reduce the excitatory stimulus amplitude: RETREAT, ESCAPE, and SWIM increase the distance between predator and $C R A Y F I S H$, and FORAGE and EAT reduce hunger by increasing the available energy.

\section{Sources of unpredictability in CRAYFISH behavior}

Much of CKAYFISH's behavior is readily understandable if not precisely predictable: after spending a period of time in the shelter, CRAYFISH suddenly leaves and moves in the dircction of the food source; upon arriving at the food, CRAYFISH EATs, RESTs, and then RETREATs to the shelter. However, on some occasions in which stimulus conditions are similar, unexpected variants of familiar behavior patterns appear. These occurrences are at first surprising; intuition might suggest that a deterministic system like CRAYFISH should exhibit predictable behavior that changes only gradually as initial conditions change.

$C R A Y F I S H$ exhibits two kinds of unpredictable responses. The first results from the coincidence of observables, such as the encounter of the predator and CRAYFISH. In the simulation of Figure 2, CRAYFISH leaves the shelter to FORAGE for food at $155 t$, whereas in that of Figure 1, CRAYFISH's departure to FORAGE is unexpectedly delayed until $280 t$ by the approach of the predator. This kind of unpredictability is readily explicable in terms of $C R A Y F I S H$ 's normal responses to the new stimulus: the predator cxcited RETREAT which inhibited FORAGE and disinhibited HIDE.

The second kind of unpredictable response results from close encounters of system command values with their inhibitory and behavioral thresholds. Small differences in the initial value of a parameter (e.g., amount of food available) propagate through the simulation and lead to differences in the command value of one or more systems (e.g., EAT) as it approaches its inhibitory or behavioral threshold (as in Fig. 4B). Mutual inhibition between systems can amplify these differences in command value and increase the chance that they will straddle an inhibitory or behavioral threshold. When this happens, it is likely that two different patterns of behavior will occur from that time on. $C R A Y F I S H$ has seven pairs of thresholds that are approached or crosscd repcatedly by system command values during any simulation, and these hidden encounters provide many opportunities for small differences in initial conditions to produce bifurcating histories of behavior.

\section{Sensitivity of CRAYFISH behavior to initial conditions}

The sensitivity of CRAYFISH's behavior to small changes in the initial amount of food available extends to similar small changes in the initial values of other stimulus parameters, including energy and the relative positions of the food, shelter, and CRAYFISH. As each parameter is varied by small increments while the others remain constant, a gradual change in the sequence of behaviors is often interrupted by the appearance of alternate sequences that are also adaptive responses to the stimulus conditions.

If each stimulus parameter is thought of as one dimension of a multidimensional parameter space, then each point in the space describes a possible set of initial conditions. The sequence of behaviors that results from those conditions can be associated with (mapped onto) that point. Small volumes of this space would bc associatcd with similar behavioral sequences, but these volumes would have sharp borders where movement along one dimension (parameter value) abruptly results in a different behavioral sequence. If the environment of the CRAYFISH were made more complex by adding other sources of food, shelters, and predators, these volumes would become even smaller and perhaps shrink to a point. In this case, arbitrarily small differences in the stimulus parameters would lead to behavioral sequences that would ultimately diverge.

The sensitivity of CRAYFISH to initial conditions and the unpredictability of its responses are both characteristics of chaotic deterministic systems (Stewart and Thompson, 1986). As in other chaotic systems, all the subsystems of $C R A Y F I S H$ are deterministic, but they interact in response to a complex environment to produce unpredictable, nonrepeating patterns of behavior. Animals face environments that are much more complex and those that employ decision-making mechanisms similar to CRAYFISH will behave in a similarly unpredictable manner, independent of any stochastic process that might also be present. These simulation results suggest that the unpredictability of animal behavior, which has survival value for both predator and prey, may result in part from the chaotic behavior of complex, deterministic mechanisms for decision-making.

\section{Robustness of CRAYFISH}

Any mechanism of decision-making that might be used by animals must be robust; the tolerances of synaptic processes that mediate neuronal interactions should not be small. In $C R A Y$ $F I S H$, these synaptic processes are represented by the inhibitory coefficients that determine the strength of the inhibition that one system directs at another. $C R A Y F I S H$ is robust because it behaves well when the inhibitory coefficients are all decreased by $50 \%$ or increased by $20 \%$.

When the inhibitory coefficients are increased by more than 
$20 \%$, some of the command systems oscillate in response to certain stimulus conditions. This type of oscillation occurs in recurrent inhibitory networks and increases in severity with the size of the inhibitory coefficients (Edwards, 1983). The oscillations appear when two or more command systems are strongly cxcited and mutually inhibit each other. The excitation crokes strong simultaneous responses, but these produce simultaneous mutual inhibition that then depresses their command values. The disinhibition that follows allows the excitation to drive the command values up again to start the next cycle.

In CRAYFISH, these oscillations are artificially enhanced by the lack of rise- and fall-times in the responses of each system to its excitation and inhibition. The responses are directly proportional to the values of excitation and inhibition $1 t$ before; rise- and fall-times are 0 . As a result, oscillations occur that have a period of $2 t$. In most neural systems, rise-times are determined by cellular characteristics and by the input amplitude; in general, stronger inputs evoke responses that rise faster and reach threshold sooner than the responses to weaker inputs. Incorporation of such response kinetics in CRAYFISH would allow a more strongly excited command system to inhibit a weakly excitcd system before it had a chance to inhibit the stronger system, and so would minimize the oscillation produced by reciprocal inhibition. In this circumstance, the inhibitory coefficients could be varied over a still larger range without producing unwanted oscillation.

\section{Individuality and selection of parameter values for CRAYFISH}

The sensitivity of CRAYFISH's behavior to small differences in single inhibitory coefficients (Fig. 6) enables CRAYFISH models with different coefficients to be recognized as individuals. CRAYFISH with largely similar coefficients will behave similarly, although their behavior may be more sensitive to differences in the values of some coefficients than to others. These individual differences in behavior provided a means for selecting coefficient values during creation of CRAYFISH: values were screened by testing their effects on behavior until a combination that produced reasonable characteristics was found. Parameter values that produced maladaptive or unrealistic behavior by the $C R A Y F I S H$ were rejected. Rejected parameter values included those that would allow the CRAYFISH to be caught easily by the predator, or that would fail to move the hungry CRAYFISH toward the food in a timely fashion, or that would produce oscillations in the responses of mutually inhibitory command systems.

As in natural selection, this artificial selection procedure demonstrated that only certain relationships between parameter values would work, given the behavior of the predator and the sensory, motor, and metabolic rate properties of the $C R A Y$ FISH. For instance, it was important that the inhibition produced by ESCAPE be greater than any of the others, that EAT strongly inhibit FORAGE, and the FORAGE inhibit the predator avoidance systems (DEFENSE, RETREAT, ESCAPE, SWIMMING, and HIDE) less than they inhibit it. These relationships express priorities that are adaptive in particular situations that are likely to occur, such as an encounter with a predator while outside the shelter. Should the properties of the predator (speed, distance at which CRAYFISH is detected) be changed, the current set of excitatory and inhibitory coefficients could be replaced with another set that enables CRAYFISII to cope with the new situation.

\section{Displacement behavior in CKAYFISH and crayfish}

The mechanism for behavioral choice in CRAYFISH is similar to one described by Ludlow (1980) in which subsystems for feeding, drinking, singing, and preening compete through mutual inhibition to control behavior in Barbary Doves. Unlike CRAYFISH, Ludlow's "Decision-Maker" cannot produce displacement behavior in the absence of "fatigue" of competing subsystems. This inability results from having the inhibitory and behavioral thresholds be equal, and having inhibitory coefficients with values greater than 1 . Only one system, that which governs the behavior of the model, can inhibit other systems. In most of the CRAYFISH simulations discussed here, behavioral threshold was higher than inhibitory threshold, and the inhibitory coefficients were less than or equal to 1 . Such an arrangement permits a system that does not control behavior to inhibit other systems, including the one currently in control. This enables mutual inhibition between two competing systems to drive each other below behavioral threshold, and allow a previously blocked behavior to be expressed.

To my knowledge, displacement behavior has not been reported in crayfish, though it may occur. $\Lambda$ difference between inhibitory and behavioral thresholds, which allows $C R A Y F I S H$ to produce displacement behavior, has been reported in crayfish, though it is not clear how widespread it is. Inhibition of the crayfish motor giant motor neuron, which is used exclusively in giant fiber-mediated tailflips, precedes a nongiant tailflip evoked by pinching the exopodite of the tailfan (Wine and Krasne, 1982). In another case the two thresholds are identical: inhibition of the lateral giant (LG) escape response (a somersault tailflip) is initiated by the same signal that triggers a backwards tailflip, a spike in the medial giant (MG) neuron (Roberts, 1968).

A virtue of the Decision-Maker (Ludlow, 1980) was that except for brief transitional periods, only one system was above behavioral and inhibitory threshold at a time. This was accomplished by setting the inhibitory gains (coefficients) to values greater than 1, usually 2 or higher. Like Decision-Maker, $C R A Y$ $F I S H$ will produce adaptive behavior if the inhibitory and behavioral thresholds are equal and if all the nonzero inhibitory coefficients equal 1 or 1.2. Higher values lead to the appearance of uncontrolled oscillations, which usually begin when two strongly excited systems are disinhibited by the declining response of a third system. They both will respond, then inhibit each other, then be simultaneously disinhibited, thereby beginning the next cycle. This situation is unavoidable in systems like $C R A Y F I S H$ where several mutually inhibitory systems are often excited simultaneously.

\section{Other modes of organization: hierarchical and parallel distributed processing (PDP) systems}

The pattern of organization of CRAYFISH is quite different from hierarchical systems of command and control, and from newer PDP systems. In a hierarchical scheme, a central executive responds appropriately to different contingencies by analyzing various types of incoming information, formulating a plan or motor program based on that analysis, and then issuing a set of commands to accomplish the goal. In PDP systems, an array of similar, nonspecialized processing units responds to different patterns of input by producing the desired patterns of output. These responses depend on the arrangement and strength of connections between the units; analysis of inputs and formation of outputs occur simultaneously as each processing unit 
Table 1. Coefficients of inhibition between pairs of the seven command systems

\begin{tabular}{llllllll}
\multirow{2}{*}{$\begin{array}{l}\text { Inhibited } \\
\text { system }\end{array}$} & \multicolumn{2}{l}{ Inhibiting system } \\
\cline { 2 - 7 } & ESCAPE & RETREAT & DEFENSE & HIDE & EAT & FORAGE & SWIM \\
\hline ESCAPE & - & 0.5 & 0.5 & 0.5 & 0.5 & 0.2 & 1 \\
RETREAT & 1 & - & 0.5 & 0.5 & 0.5 & 0.2 & 0.5 \\
DEFENSE & 1 & 0.5 & - & 0.5 & 0.5 & 0.2 & 0.5 \\
HIDE & 1 & 0 & 0.5 & - & 0 & 0.5 & 0 \\
EAT & 1 & 0.5 & 0.5 & 0 & - & 0 & 0.5 \\
FORAGE & 1 & 0.5 & 0.5 & 0.5 & 1 & - & 0.5 \\
SWIM & 0 & 0 & 0 & 0 & 0 & 0.2 & - \\
\hline
\end{tabular}

responds to a weighted pattern of inputs and signals from other processors (Rumelhart and McClelland, 1986).

While both the hierarchical and PDP modes of organization have been proposed to govern some aspects of nervous function (Lashley, 1951; Rosenbaum, 1987; McClelland and Rumelhart, 1986), at present they are unattractive as models of mechanisms for behavioral choice in crayfish. No central organizer of motor programs has been identified in crayfish, whereas several neural circuits that respond to specific sign stimuli and that can evoke different FAPs have been identified. Moreover, the existence of these circuits demonstrates that unlike a PDP network, the crayfish nervous system is quite heterogeneous. Nonetheless, it is possible that PDP networks do exist within sensory systems that must decode many different patterns of input (Girardot and Derby, 1988), and in motor systems that must produce many different combinations of joint angles or movement vectors (Lockery et al., 1989; Wittenberg et al., 1989).

$C R A Y F I S H$ retains some aspects of both these modes of organization. Each system is organized somewhat like a central executive, except that it is specialized to respond to one pattern of input and produce one pattern of response. Control of behavior is distributed across the set of systems, so that the sequence of behavior is governed by the sequential patterns of input across all systems and by the inhibitory interactions between them. $\Lambda$ s in PDP systems, this distributed control leads to emergent behavior patterns such as displacement behavior and the unexpected switching between alternate sequences of behavior.

\section{Neural mechanisms of behavioral choice in crayfish}

CRAYFISH was developed to determine whether mutual inhibition among command centers could produce adaptive patterns of behavior and not to provide a detailed reconstruction of parts of the crayfish nervous system. Nonetheless, two major themes of crayfish neuroethology guided the construction of $C R A Y F I S H$. First, specific stimulus configurations excite discrete neural circuits that release distinct FAPs. The defense posture and backward walking are both evoked by approaching objects that loom large in the visual field (Glantz, 1974; Beall et al., 1990). A somersault escape tailflip is triggered by a sharp tap on the abdomen (Wiersma, 1947), whereas a rearward tailflip is triggered by a sharp tap to the cephalothorax (Wine and Krasne, 1982). Swimming is evoked by a pinch of an appendage or by proprioceptive reafference following the flexion phase of a tailflip. Walking is also excited by illumination of the eyes or the caudal photoreceptors in the terminal abdominal ganglion (Kovac, 1974a,b; Edwards, 1984; Simon and Edwards, 1990).
Each of these behavioral responses can also be activated by stimulation of single central neurons or discrete groups of central neurons that have little or no overlap with neurons that activate other motor patterns (Bowerman and Larimer, 1973a,b; Krasne and Wine, 1984). In several cases, these central neurons have been shown to be excited by appropriate sign stimuli (Glantz, 1974; Wine and Krasne, 1982; Simon and Edwards, 1990), and in one case (somersault tailflip, produced by the LG interneurons) they have been shown to be necessary and sufficient for release of the behavior (Olson and Krasne, 1981).

Second, activation of a neural circuit and its FAP excites or inhibits other neural circuits and their FAPs. The LG neurons are inhibited by the MG interneurons that evoke the rearward tailflip (Roberts, 1968). LGs are also inhibited by activation of walking circuitry (Edwards et al., 1988), by proprioceptive reafference from the walking legs (Fricke and Kennedy, 1983), and during feeding (Krasne and Lee, 1988). Giant motor neurons that produce the LG tailflip are inhibited during swimming (Wine and Krasne, 1982). The stimulus threshold for LG (somersault) tailflips increases during walking, feeding, defense display, and external restraint (Wine et al., 1975; Glanzman and Krasne, 1983; Krasne and Lee, 1988; Beall et al., 1990). Conversely, all other ongoing activities are interrupted by tailflip responses or by swimming. These interruptions are mediated at least in part by inhibition of motor neurons for muscle systems not involved in escape (Kuwada and Wine, 1979; Kuwada et al., 1980). Mutual inhibition also occurs between two sets of interneurons that produce different slow abdominal movements (Moore and Larimer, 1987, 1988). Finally, swimming is inhibited during feeding if the food object is too large to be portable; if, however, the food object is readily portable, stimulus threshold for swimming is decreased (Bellman and Krasne, 1983). This last result suggests that the sign of the interactions between different systems may change, depending on context and hormonal stage (Glanzman and Krasne, 1983; Harris-Warrick and Kravitz, 1986; Kravitz, 1988).

\section{CRAYFISH as the basis for a formal model of crayfish behavior}

The success of CRAYFISH encourages the idea that mutual inhibition between neural circuits for competing FAPs organizes a large part of crayfish behavior. $C R A Y F I S H$ illustrates how quantitative descriptions of these neural systems and behaviors can provide the basis for a more realistic model of crayfish behavior. This model could demonstrate the consequences of simultaneous, dynamic interactions among these systems, and it could show whether the complex, adaptive behaviors that 
crayfish normally display can be produced by this kind of mechanism for behavioral choice.

\section{Appendix}

\section{Excitation of command systems}

The equations used to describe cxcitation of the command systems are

$$
\begin{aligned}
& \text { FORAGE: } \quad E_{\text {for }}=A_{\text {for }} * \text { FoodOdor*Hunger } /(\text { Hunger } \\
& +4) \text {, } \\
& \text { FoodOdor }=\text { FoodAmount } /\left(D_{\text {food }}+1\right) \text {, } \\
& \text { Hunger }=100 * e^{x-4 * \text { Energy) }} \text {; } \\
& \text { EAT: } \quad E_{\text {eat }}=A_{\text {eat }} * \text { FoodOdor } * \text { Hunger } /(\text { Hunger } \\
& +4 \text { ), if } D_{\text {food }} \leq 10 \text {, } \\
& E_{\text {eat }}=0, \quad \text { if } D_{\text {food }}>10 \text {; } \\
& \text { DEFENSE: } \quad E_{\mathrm{def}}=A_{\mathrm{def}} * e^{-D_{\mathrm{pred}} / L_{\mathrm{der}}} \text {; } \\
& \text { RETREAT: } \quad E_{\mathrm{ret}}=A_{\mathrm{ret}} * e^{-D_{\mathrm{pred}} / L_{\mathrm{ret}}}+3+5 * e^{-D_{\mathrm{s}} / 200} \\
& -3 * e^{-D_{3} / 50} \\
& \text { ESCAPE: } \quad E_{\mathrm{esc}}=A_{\mathrm{csc}} * e^{-D_{\mathrm{pred}} / L_{\mathrm{esc}}} \\
& \text { SWIM: } \quad E_{\text {swim }}=A_{\text {swim }} * C_{\text {csc }}\left(T_{\mathrm{csc}}\right) * e^{\left(-\left(t-T_{\mathrm{esc}} / 3\right)\right.} \text {, } \\
& \text { for } t>T_{\mathrm{esc}} \text {, } \\
& E_{\text {swim }}=0, \quad \text { for } t<T_{\text {esc }} \text {; } \\
& \text { HIDE: } \quad \text { if } D_{\mathrm{s}} \leq 20 \text {, then } E_{\text {hid }}=A_{\text {hid }} \text {, } \\
& \text { if } D_{\mathrm{s}}>20 \text {, then } E_{\text {hid }}=0 \text {; }
\end{aligned}
$$

where $A_{\text {for }}$, etc., are the excitatory coefficients for each command system; $D_{\text {pred }}, D_{\text {food }}$, and $D_{\mathrm{s}}$ are the distances between the crayfish and the predator, food, and shelter, respectively; and $L_{\text {def }}, L_{\text {ret }}$, and $\mathrm{L}_{\text {esc }}$ are length constants for excitation of each of those command systems. The excitatory coefficients are $A_{\text {for }}=500$, $A_{\text {cat }}=500, A_{\text {def }}=8, A_{\text {ret }}=15, A_{\text {esc }}=45, A_{\text {swim }}=1, A_{\text {hid }}=6$. The length constants are $L_{\mathrm{def}}=135, L_{\mathrm{ret}}=45, L_{\mathrm{esc}}=15$. The variable $C_{\text {esc }}\left(T_{\text {esc }}\right)$ is the value of the command function for escape at the time an escape is triggered. Each command function is equal to the excitation of the system minus the inhibition it receives from other systems.

\section{Inhibition of the command systems}

The inhibition directed by one system against another is equal to the product of the command value of the inhibiting system (if it is $\geq 1$ ) and an inhibitory coefficient. If the command value is less than 1 , the inhibition is 0 . The values of the coefficients are given in Table 1.

\section{CRAYFISH movement rates produced by each command system}

The $C R A Y F I S H$ movement rates $(d / t)$ produced by each command system are FORAGE, 3; EAT, 0; DEFEND, 0; RETREAT, 2; ESCAPE, 50; SWIM, 25; HIDE, 0.

\section{Metabolic rates of CRAYFISH during behavior produced by each command system}

The rates at which energy is lost $(-)$ or gained $(+)$ by $C R A Y$ FISH are FORAGE, -0.004 ; EAT, +0.05; DEFEND, -0.002; RETREAT, -0.004; ESCAPE, -0.02; SWIM, 0.01; HIDE, -0.002 .

\section{References}

Beall SP, Langley DJ, Edwards DH (1990) Inhibition of escape tailflip in crayfish during backward walking and the defense posture. J Exp Biol 152:577-582.

Bellman K, Krasne FB (1983) Adaptive complexity of interactions between feeding and escape in crayfish. Science 221:779-781.

Bowerman RF, Larimer JL (1973a) Command fibres in the circumesophageal connectives of crayfish. I. Tonic fibres. J Exp Biol 60:95117.

Bowerman RF, Larimer JL (1973b) Command fibres in the circumesophageal connectives of crayfish. II. Phasic fibres. J Exp Biol 60: 119-134.

Edwards DH (1983) Response vs. excitation in response-dependent and stimulus-dependent lateral inhibitory networks. Vision Res 23: 469-472.

Edwards DH (1984) Crayfish extraretinal photoreception. I. Behavioural and motoneuronal responses to abdominal illumination. J Exp Biol 109:291-306.

Edwards DH, Simon TW, Leise EM, Fricke RA (1988) Crayfish "backward walking" neurons inhibit LG command neuron. Soc Neurosci Abstr 14:999.

Fricke RJ, Kennedy D (1983) Inhibition of mechanosensory neurons in the crayfish. III. Presynaptic inhibition of primary afferents by a central proprioceptive tract. J Comp Physiol 153:443-453.

Girardot M-N, Derby CD (1988) Neural coding of quality of complex olfactory stimuli in lobsters. J Neurophysiol 60:303-324.

Glanzman DL, Krasne FB (1983) Serotonin and octopamine have opposite modulatory effects on the crayfish's lateral giant escape reaction. J Ncurosci 3:2263-2269.

Glantz RM (1974) Defense reflex and motion detector responsiveness to approaching targets: the motion detector trigger to the defense reflex pathway. J Comp Physiol 95:297-314.

Harris-Warrick RM, Kravitz EA (1986) Cellular mechanisms for modulation of posture by octopamine and serotonin in the lobster. $\mathrm{J}$ Neurosci 4:1976-1993.

Heitler WJ, Pearson KG (1980) Non-spiking interactions and local interneurones in the central pattern generator of the crayfish swimmeret system. Brain Res 187:206-211.

Kennedy D, Davis WJ (1974) The organization of invertebrate motor systems. In: Handbook of physiology, Vol 2, Neurophysiology, 2nd ed (Kandel ER, ed), pp 1023-1087. Bethesda, MD: American Physiological Society.

Kovac M (1974a) Abdominal movements during backward walking in the crayfish. I. Properties of the motor program. J Comp Physiol 95:61-78.

Kovac M (1974b) Abdominal movements during backward walking in the.crayfish. II. The neuronal basis. J Comp Physiol 95:79-94.

Kovac MP, Davis WJ (1980) Neural mechanisms underlying behavioral choice in Pleurobranchaea. J Neurophysiol 43:469-487.

Krasne FB, Lee SC (1988) Response-dedicated trigger neurons as control points for behavioral actions: selective inhibition of lateral giant command neurons during feeding in crayfish. J Neurosci 8:37083712.

Krasne FB, Wine JJ (1984) The production of crayfish tailflip escape responses. In: Neural mechanisms of startle behavior (Eaton RC, ed), pp 179-212. New York: Plenum.

Kravitz EA (1988) Hormonal control of behavior: amines and the biasing of behavioral output in lobsters. Science 241:1775-1781.

Kuwada J, Wine JJ (1979) Crayfish escape behaviour: commands for fast movement inhibit postural tone and reflexes, and prevent habituation of slow reflexes. J Exp Biol 79:205-224.

Kuwada J, Hagiwara G, Wine JJ (1980) Postsynaptic inhibition of crayfish tonic flexor motor neurones by escape commands. J Exp Biol 85:344-347.

Lashley K (1951) The problem of serial order in behavior. In: Cerebral mechanisms in behavior (Fentress LA, ed), pp 112-136. New York: Wiley.

Lockery SR, Wittenberg G, Kristan WB, Sejnowski TJ (1989) Connections of identified interneurons in the leech arise in neural networks trained by back-propagation. Soc Neurosci Abstr 5:1119.

Lorenz K (1950) The comparative method in studying innate behaviour patterns. Sym Soc Exp Biol 4:221-268.

Lorenz K (1982) The foundations of ethology. New York: Simon and Schuster.

Ludlow AR (1980) The evolution and simulation of a decision maker. In: Analysis of motivational processes. (Toates FM, Halliday TR, eds), pp 273-296. London: Academic.

McClelland JL, Rumelhart DE (1986) Parallel distributed processing, Vol 2, Psychological and biological models, p 611. Cambridge, MA: MIT Press. 
McFarland DJ (1974) Time-sharing as a behavioural phenomenon. Advan Study Behav 5:201-225.

McFarland DJ (1985) Animal Behavior. Menlow Park, CA: Benjamin/ Cummings.

Moore DL, Larimer JL (1987) Neural control of a cyclic postural behavior in crayfish, Procambarus clarkii. J Comp Physiol A 160 169-179.

Moore DL, Larimer JL (1988) Interactions between the tonic and cyclic postural motor programs in the crayfish abdomen. J Comp Physiol A 163:187-199.

Olson GC, Krasne FB (1981) The crayfish lateral giants as command neurons for escape behavior. Brain Res 214:89-100.

Paul DH, Mulloney B (1986) Intersegmental coordination of the swimmeret rhythms in isolated nerve cords of the crayfish. J Comp Physiol A 158:215-224.

Roberts A (1968) Recurrent inhibition in the giant-fibre system of crayfish and its effect on the excitability of the escape response. I Exp Biol 48:545-567.

Rosenbaum DA (1987) Hierarchical organization of motor programs. In: Higher brain functions (Wise SP, ed), pp 45-66. New York: WileyInterscience.

Rumelhart DE, McClelland JL (1986) Parallel distributed processing, Vol 1, Foundations, p 547. Cambridge, MA: MIT Press.

Schrameck JE (1970) Crayfish swimming: alternating motor output and giant fiber activity. Science 169:698-700.
Simon TW, Edwards DH (1990) Light-evoked walking in crayfish: behavioral and neuronal responses triggered by the caudal photoreceptor. J Comp Physiol A 166:745-755.

Stewart HB, Thompson JM (1986) Nonlinear dynamics and chaos. New York: Chichester (Wiley)

Tinbergen N (1951) The study of instinct. Oxford: Clarendon. (Reprinted 1989.$)$

Wiersma CAG (1947) Giant nerve fiber system of crayfish: a contribution to comparative physiology of synapse. J Neurophysiol 10:2338

Wiersma CAG, Ikeda K (1964) Interneurons commanding swimmeret movements in the crayfish, Procambarus clarkii (Girard). Comp Biochem Physiol 12:509-525.

Wiersma CAG, Yamaguchi T (1967) Integration of visual stimuli by the crayfish central nervous system. J Exp Biol 47:409-431.

Wine JJ, Krasne FB (1982) The cellular organization of crayfish escape behavior. In: The biology of crustacea, Vol 4, Neural integration and behavior (Sandeman DC, Atwood HL, eds), pp 242-292. New York: Academic.

Wine JJ, Krasne FB, Chen L (1975) Habituation and inhibition of the crayfish lateral giant fibre escape response. J Exp Biol 62:771-782.

Wittenberg G, Lockery SR, Kristan WB (1989) Intersegmental interneurons contribute to multiple behaviors in the leech. Soc Neurosci Abstr 15:1119. 